\title{
MICROFÁCIES DE SEDIMENTOS CLÁSTICOS
}

\author{
J. M. MABESOONE*
}

\begin{abstract}
The concept of microfacies as proposed by Carozzi has been applied for non-fossiliferous, clastic sediments, taking as an example the Piranhas Formation of the Rio do Peixe basin.

A great number of detailed microfacies types has been distinguished by determination in thin section of petrography, diagenesis, medium size, morphometry, micro-structures and maturity of sandstones, and as far as possible also of siltstones, claystones and shales. These detailed microfacies have been grouped into five composed microfacies.

Interpreting the occurrences of samples in the studied section and the composed microfacies to which they belong, permitted the conclusion of a deposition in a piedmont - alluvial fan environment, in five successive rhythms.
\end{abstract}

INTRODUÇÃo Nos últimos anos, o estudo dos sedimentos em lâminas petrográficas recebeu grande impulso. Após a obra básica de Carozzi (1960), sobre a petrografia sedimentar microscópica, grande número de aplicações e aperfeiçoamentos foi publicado.

Foi o mesmo Carozzi que, à base do estudo microscópico das rochas sedimentares, introduziu o conceito das microfácies $(1950,1958)$. A finalidade do estudo dessas microfácies é contar e descrever os caracteres principais dos componentes microscópicos, além de traçar sua variação numa direção tanto horizontal como vertical. Tal estudo permite uma comparação mais precisa com logs geofísicos e zonação de fósseis-índice.

Estudam-se, assim, os minerais detríticos com seus índices de freqüência e clasticidade (diâmetro máximo aparente), os minerais autígenos, as microfaunas e a matriz.

O método foi aplicado, até agora, com maior frequêencia nos calcários, nos quais os componentes bióticos são tão significativos para sua interpretação de origem e procedência. Podemos mencionar, por exemplo, os trabalhos de Carozzi (1961), de Heath, Lumsden e Carozzi (1967), e de Carozzi, Tibana e Tessari (1973), todos sobre a grande variação nas seqüências de rochas calcárias. Porém, uma aplicação em sedimentos clásticos, sem fósseis, não mais foi feita, após o trabalho original de Carozzi (1958). Devido aos nossos estudos de petrografia sedimentar em seqüências essencialmente clásticas e afossilíferas, tentamos aplicar o método das microfácies também nesses tipos de rocha e testar sua utilidade na interpretação da origem e procedência do material.

Método de estudo Dos sedimentos clásticos, os arenitos são os melhores pará serem estudados em lâminas petrográficas. Os conglomerados não são muito favoráveis para tal estudo, devido ao tamanho grande dos seus componentes, enquanto que os siltitos, os argilitos e os folhelhos não são devido ao tamanho pequeno. Assim, uma subdivisão maior em tipos diferentes é apenas possível no caso dos arenitos.

Para a análise petrográfica dos arenitos, recomenda-se o esquema dado por Pettijohn, Potter e Siever (1972; apêndice, pp. 584-600). Dessa maneira, precisam ser determinados:

1) elementos detríticos principais e nome da rocha - os grãos de quartzo, feldspato e fragmentos de rocha, cuja proporção relativa determina o nome do arenito (veja Mabesoone, 1968; Fig. 5-2);

*Instituto de Geociências, Universidade Federal de Pernambuco, Recife (PE). Pesquisador-conferencista hon. do CNPq 
2) elementos detríticos acessórios - os grãos dos elementos que ocorrem em menores proporções, como, por exemplo, micas, minerais pesados, glauconita, etc.;

3) fósseis - notar se há a presença eventual de fósseis ou fragmentos bióticos;

4) matriz e cimento - o material que preenche os interstícios e cimenta a massa, sendo geralmente argila, óxidos de ferro, calcita ou sílica;

5) fenômenos diagenéticos - determinação da fase diagenética em que se encontra a rocha, estudando-se os contatos entre os grãos e as neoformações de minerais secundários (veja Mabesoone, 1973);

6) tamanho - menciona-se, em termos gerais, o tamanho médio do sedimento, além de determinar-se o "índice de clasticidade" ou diâmetro máximo aparente;

7) arredondamento e esfericidade - descrevem-se os tipos e suas variaçôes com o tamanho;

8) microestrutura - deve-se observar se, por acaso, há concentração de certos minerais em zonas ou lentes, ou se aparece uma microlaminação cruzada;

9) maturidade textural - segundo a Tab. A-1 (p. 588, em Pettijohn, Potter e Siever, 1972).

No caso dos conglomerados, pode-se apenas fazer uma descrição geral macroscópica e juntar os dados com a microscopia da matriz arenosa ou argilosa.

Os siltitos e os argilitos, devido ao tamanho pequeno dos seus componentes individuais, são os mais dificeis para um estudo petrográfico. Os únicos ítens que podem ser deter* minados, são os seguintes:

10) presença de minerais transparentes - em geral, trata-se de quartzo do tamanho silte, anguloso ou picotado pelo ataque da argila e outras substâncias agressivas;

11) disposição do material microclástico - observar se há laminação, concentração em lentes ou zonas irregulares;

12) presença de óxidos de ferro - responsável pela cor da rocha;

13) minerais autígenos - se existem neoformações de minerais secundários, como, por exemplo, feldspatos.

Apesar dos poucos itens a serem estudados, pode-se obter uma idéia da disposição textural e estrutural do depósito microclástico.

Com esses dados, é necessário, depois, fazer-se um agrupamento de tal maneira que se obtém um número reduzido de tipos de microfácies.

APLICACÃO Carozzi (1958) estudou as amostras de furos, tomadas em intervalos curtos e apresentou os dados obtidos em forma de curvas, representando alguns elementos importantes.

No trabalho de Carozzi, Tibana e Tessari (1973), embora se trate de calcários, fez-se a apresentação em forma de um gráfico quadrangular, em que cada coluna representa um elemento com, para cada amostra, a freqüência desse elemento (Fig. 3 do referido trabalho). À base dessas freqüências foram determinadas as microfácies detalhadas e, depois, devido a seu grande número, reduzidas em poucas microfácies compostas, indicativas para os ambientes de formação.

Esse último método parece ser o melhor para obter-se uma boa idéia das microfácies detalhadas, podendo também ser aplicado para os sedimentos clásticos.

Como exemplo, damos aqui um perfil nos sedimentos clástıcos pertencentes à Formação Piranhas, unidade superior do Grupo Rio do Peixe, procedente do furo estratigráfico LFst-1-Pa (Lagoa do Forno, a SE da cidade de Sousa, Paraíba). A espessura dessa formação é de $105 \mathrm{~m}$; as amostras foram tomadas com intervalos de $5 \mathrm{~m}$. 
Tabela I - Elementos determinados nas lâminas petrográficas das amostras estudadas

\begin{tabular}{|c|c|c|c|c|c|c|c|c|c|c|c|c|c|c|}
\hline & & 1 & 2 & 4 & 5 & 6 & 7 & & 8 & 9 & 10 & 11 & 12 & 13 \\
\hline 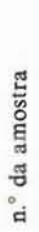 & 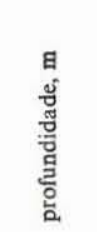 & 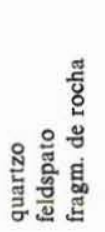 & 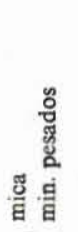 & 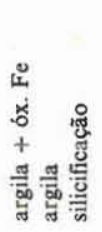 & 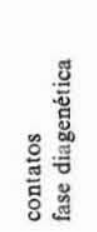 & 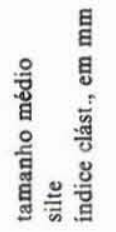 & 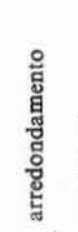 & 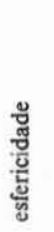 & 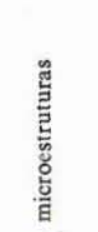 & 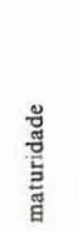 & 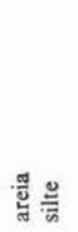 & 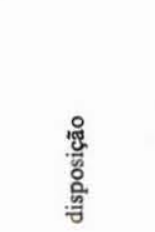 & 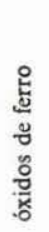 & 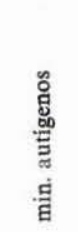 \\
\hline 1 & $0-5$ & $D F F$ & RO & $-P-$ & $T R f m$ & $m-2,00$ & $A / S A$ & .8 & & imat. & & & & \\
\hline 2 & $5-10$ & $D P P$ & $P O$ & $F--$ & $T f$ & $f F 0,50$ & $A / S A$ & .7 & & imat. & & & & \\
\hline 3 & $10-15$ & & & & & & & & & & $P A$ & $\begin{array}{l}\text { areia fina } \\
\text { em zonas }\end{array}$ & $D$ & \\
\hline 4 & $15-20$ & $F F D$ & $O R$ & $F--$ & $-f$ & $c o-10$ & $A / S A$ & - & & imat. & & & & \\
\hline 5 & $20-25$ & $F F D$ & $O R$ & $-P-$ & $-f$ & co $-6,00$ & $A / S A$ & - & & imat. & & & & \\
\hline 6 & $25-30$ & $D F O$ & RO & $A--$ & $T f$ & $f-0,40$ & A & .8 & & imat. & & & & \\
\hline 7 & $30-35$ & $D A R$ & RO & $-P R$ & $T R \mathrm{fm}$ & $m-0,40$ & $A$ & .9 & $\begin{array}{l}\text { lamin. } \\
\text { indist. }\end{array}$ & imat. & & & & \\
\hline 8 & $35-40$ & $D A R$ & 00 & $-F-$ & $T R \mathrm{fm}$ & $m-2,00$ & $A$ & .7 & & imat. & & & & \\
\hline 9 & $40-45$ & & & & & & & & & & $R A$ & $\begin{array}{l}\text { silte em } \\
\text { zonas }\end{array}$ & $D$ & feldsp. \\
\hline 10 & $45-50$ & $D F R$ & $O R$ & $F--$ & $T R f m$ & $m-1,50$ & $A$ & .7 & $\begin{array}{l}\text { argila } \\
\text { lentes }\end{array}$ & imat. & & & & \\
\hline 11 & $50-55$ & $D F R$ & $O R$ & $A--$ & $T R \mathrm{fm}$ & $m-1,50$ & $A$ & .6 & $\begin{array}{l}\text { argila } \\
\text { zonada }\end{array}$ & imat. & & & & \\
\hline 12 & $55-60$ & & & & & & & & & & $R D$ & $\begin{array}{c}\text { óx. de ferro, } \\
\text { manchas }\end{array}$ & $D$ & \\
\hline 13 & $60-65$ & & & & & & & & & & $R F$ & $\begin{array}{l}\text { silte, areia, } \\
\text { manchas }\end{array}$ & $D$ & \\
\hline 14 & $65-70$ & $A A A$ & $0 O$ & $-P-$ & $T R \mathrm{fm}$ & $\boldsymbol{m}-2,00$ & A & .7 & & imat. & & & & \\
\hline 15 & $70-75$ & $A A F$ & $O R$ & $F--$ & $T R \mathrm{fm}$ & $g-2,00$ & $A / S A$ & 8 & $\begin{array}{l}\text { lamin. } \\
\text { indist. }\end{array}$ & imat. & & & & \\
\hline 16 & $75-80$ & $D F R$ & $R O$ & $A--$ & $T f$ & $f-0,35$ & $A$ & .8 & $\begin{array}{l}\text { lamin. } \\
\text { indist. }\end{array}$ & imat. & & & & \\
\hline 17 & $80-85$ & $D P R$ & oo & $-A-$ & $T f$ & $m P 0,50$ & $A$ & 8 & imat. & & & & & \\
\hline 18 & $85-90$ & & & & & & & & & & $O D$ & $\begin{array}{c}\text { óx. de ferro, } \\
\text { manchas }\end{array}$ & $D$ & \\
\hline 19 & $90-95$ & $D A P$ & $O R$ & $-F-$ & $T R f m$ & $m-2,00$ & $A$ & .8 & & imat. & & & & \\
\hline 20 & $95-100$ & $D P R$ & RO & $A--$ & $T f$ & $m-0,35$ & $A$ & .7 & & imat. & & & & \\
\hline 21 & $100-105$ & & & & & & & & & & $F A$ & $\begin{array}{l}\text { areia em } \\
\text { zonas }\end{array}$ & $D$ & \\
\hline
\end{tabular}

Legenda. Freqüência, para os elementos 1, 2, 4, 10 e 12: $O$, ausente; $R$, raro $(0-5 \%)$; $P$, presente $(5-10 \%) ; F$, freqüente $(10-25 \%) ; A$, abundante $(25-50 \%) ; D$, dominante (mais que $50 \%$ ). Elemento 5: $T$, contato tangencial; $R$, contato reto; $f$, diagênese fraca; $m$, diagênese média. Elemento 6 : $c 0$, conglomerático; $g$, arenoso grosseiro; $m$, arenoso médio; $f$, arenoso fino - para a coluna "silte" aplica-se a freqüência dos elementos 1 e outros. Elemento 7: $A$, anguloso; $S A$, subanguloso - esfericidade segundo a Fig. 11-26 em Mabesoone (1968). Observação. O elemento 3 - presença de fósseis - foi omitido devido ao fato de todas as amostras terem se mostrado afossilíferas.

A Tab. I reúne todos os dados que podiam ser tirados das lâminas petrográficas, segundo os itens mencionados.

De posse desses dados, podemos agora estabelecer as microfácies detalhadas, no sentido de Carozzi, Tibana e Tessari (1973). Desde que a finalidade do estudo seja a reconstituição dos ambientes de deposição e a origem da rocha, se for em pormenores, essas microfácies devem fornecer o máximo de informações sobre o assunto. Na Tab. II, assim, 
Tabela II - Microfácies detalhadas $(A)$ e microfácies distinguidas nas amostras estudadas $(B)$

\begin{tabular}{llll}
\hline (A) & \multicolumn{1}{c}{ Nome da rocha } & \multicolumn{1}{c}{ Tamanho médio } & Matriz e/ou cimento \\
\hline$Q$ arenito quartzoso & $P$ conglomerático & & $\begin{array}{l}\text { com matriz argilosa } \\
P \text { arenito protoquartzoso }\end{array}$ \\
& $G$ arenoso grosseiro & & $f$ com matriz/cimento \\
& & & argilo-ferruginoso \\
$L$ arenito lítico e subgrauvaca & $M$ arenoso médio & $c$ com cimento calcitico \\
$G$ grauvaca lítica e feldspática & $F$ arenoso fino & $S$ silicificação \\
$A$ arcósio e subarcósio & $A$ arenoso (em microclásticos) & \\
$S$ siltito & $S$ síltico & \\
$C$ argilito e folhelho & $C$ argiloso & \\
\hline
\end{tabular}

(B)

$Q M a$ arenito quartzoso médio, com matriz argilosa

PMf arenito protoquartzoso médio, com matriz/cimento argilo-ferruginoso

$P M a$ arenito protoquartzoso médio, com matriz argilosa

$P F f$ arenito protoquartzoso fino, com matriz/cimento argilo-ferruginoso

PSf arenito protoquartzoso síltico, com matriz/cimento argilo-ferruginoso

am. 20

ams. 10 e 11

am. 17

ams. 6 e 16

GPf grauvaca conglomerática, com matriz/cimento argilo-ferruginoso

$G P a$ grauvaca conglomerática, com matriz argilosa

GGf grauvaca grosseira, com matriz/cimento argilo-ferruginoso

$G M a$ grauvaca média, com matriz argilosa

$A M a$ arcósio ou subarcósio médio, com matriz argilosa

$S A f$ siltito arenoso, com óxidos de ferro e argila

$S C f$ siltito argiloso, com óxidos de ferro

CSf argilito siltico, com óxidos de ferro

am. 2

am, 4

am. 5

am. 15

ams. 1 e 14

ams. 7,8 e 19

am. 21

ams. 12 e 18

ams. 3,9 e 13

apresentamos as microfácies detalhadas e aquelas distinguidas na seqüência em apreço, com as amostras atribuídas às mesmas.

Como se pode observar, os tipos de microfácies são muitos e ainda não foram incluídos parâmetros como arredondamento, microestrutura e maturidade. Em relação ao arredondamento, nota-se pouca variação, com a maior parte dos grãos angulosos até subangulosos. Microestruturas foram raramente observadas, com apenas uma certa laminação indistinta em algumas camadas e uma zonação ou ocorrência em lentes de alguns componentes em outras. A maturidade, segundo o roteiro de Folk (vide Pettijohn, Potter e Siever, 1972; Tab. A-1), mostrou que todas as amostras são imaturas, sem exceção.

Tabela III - Microfácies compostas, distinguidas ná seqüência estudada

$Q M a, P M f, P M a-1:$ arenitos quartzosos e protoquartzosos médios (ams. 10,11,17 e 20)

$P F f, P S f-2$ : arenitos protoquartzosos finos e silticos (ams. 2,6 e 16)

GPf, GPa, GGf, GMa - 3: grauvacas conglomeráticas até médias (ams. 1, 4, 5, 14 e 15)

$A M a-4:$ arcósios e subarcósios médios (ams. 7,8 e 19)

$S A f, S C f, C S f-5:$ microclásticos (siltitos e argilitos ferruginosos)

(ams. 3, 9, 12, 13, 18 e 21) 
Desde que a Tab. III mostra umas treze microfácies diferentes, cada uma com poucos exemplos, seguimos a sugestão de Carozzi, Tibana e Tessari (1973), estabelecendo microfácies compostas. Dessa maneira, na Tab. III, apresentamos as cinco microfácies compostas resultantes, cada uma agora com mais amostras e com um número quase igual em cada grupo.

INTERPRETAÇÃO Para a interpretação da seqüência, como um conjunto, foram comparados os dados das microfácies compostas, com aqueles publicados por Medeiros, Schaller e Friedman (1971) e por Pettijohn, Potter e Siever (1972, Cap. 11).

As fácies petrográficas aparecem muito variadas, na Formação Piranhas. Há uma alternância de arenitos imaturos, com grandes percentagens de feldspatos e fragmentos de rocha, numa matriz argilosa. Uma tal seqüência caracteriza os ambientes aluviais e a parte continental de deltas. Restringindo mais ainda o provável ambiente de deposição, pode-se pensar num ambiente de cones aluviais (ou fácies em leque). As características desse ambiente são mencionadas na Tab. IV (segundo Medeiros, Schaller e Friedman, 1971; Tab. II). Essa interpretação se dá muito bem para a seqüência aqui estudada, não apenas pelos dados das microfácies compostas, mas também pelas observações de campo (Braun, 1970).

Em detalhe, podemos apresentar as conclusões que seguem, sobre as microfácies compostas.

1) Arenitos quartzosos e protoquartzosos médios. São, em geral, os mais maduros, porém, no caso da Formação Piranhas, a grande quantidade de argila, com ou sem óxidos de ferro, torna-os bastante imaturos. Esse tipo de arenito é muito comum, especialmente na tectofácies do molasse, isto é: derivado de uma área com um certo relevo, como depósito correlativo. Trata-se de uma procedência bastante local, possivelmente perto desse relevo forte. A origem é como um arenito aluvial, depositado por meio de rios bem poderosos perto de áreas em soerguimento.

Tabela IV - Características do ambiente de cones aluviais (fácies em leque). (Segundo Medeiros, Schaller e Friedman, 1971, Tab. II)

Litologia

Textura

Estruturas sedimentares

Geometria

Associação

Vários
As partículas variam de tamanho silte e argila a blocos. Má seleção. Partículas de angulosas a subarredondadas. As cores vermelhas são comuns, mas pode ocorrer cor cinza. Arcósios, conglomerados, grauvacas são as rochas principais. Interestratificação de arenitos, siltitos e folhelhos são comuns.

Granulação: de muito fino a blocos. Matriz argilosa ou arenosa. A distribuição da freqüência é polimodal.

Estratificação: de indistinta a regular. Canais (corte e preenchimento) com estratificação cruzada. Seixos imbricados e formando pavimentos. Depósitos lenticulares em forma de cone e leque. Parte superficial côncava, com declividade suave. Perfil transversal da superficie convexo. $\mathrm{O}$ ângulo de mergulho raramente excede $10^{\circ}$.

Associados com depósitos estratificados de playas em áreas desérticas. Presentes corridas de lama em regiões de clima seco. Com depósitos fluviais e sedimentos eólicos.

Depósitos extensos, atingindo grandes espessuras, formando-se ao longo de escarpas de falha, em áreas tectonicamente ativas. Bacias em forma de fossa (graben) e semifossa apresentam condições favoráveis para deposição. Troncos de árvores e ossos de vertebrados podem estar presentes. 
2) Arenitos protoquartzosos finos e sílticos. Possuem uma origem e procedência como o grupo anterior, porém depositados por meio de rios menos poderosos e sujeitos a um maior intemperismo.

3) Grauvacas conglomeráticas até médias. Incluem ambos os tipos, lítico e feldspático; a matriz argilosa é caráter comum e importante. Esse tipo de arenito indica um ambiente tectônico especial, conseqüência de um evento instantâneo no movimento tectônico de soerguimento, com deposição rápida. O caso da Formação Piranhas é especial por se tratar de grauvacas não-marinhas.

4) Arcósios e subarcósios. São presentes apenas de tamanho médio, com matriz argilosa. A presença de muito feldspato num arenito deve-se, comumente, a um relevo forte com erosão e deposição rápida, mais do que a circunstâncias climáticas rigorosas. Dessa maneira, feldspatos frescos são facilmente incorporados no sedimento. $O$ ambiente de deposição deve ter sido aluvial com correntes fortes numa área de erosão acelerada.

5) Siltitos e argilitos ferruginosos. Encontram-se intercalados em certos níveis, na sequeência arenítica. Uma característica comum é a grande quantidade de óxidos de ferro concentrada nessas frações finas, tornando o depósito vermelho. Tal fenômeno é típico de uma fase siderolítica, de deposição no piemonte (Millot, 1964). O depósito microclástico foi aparentemente sedimentado, nesse ambiente, por meio de rios que, de repente, diminúram suas velocidades até quase zero ou, fora das zonas com correntes, em ambientes mais pantanosos. As pequenas lentes de areia fina nesses sedimentos parecem apontar a segunda idéia.

HISTÓRIA DA DEPOSIÇÃO DA FORMAÇÃO PIRANHAS Com esses dados, sobre os depósitos nas microfácies compostas, pode ser traçada uma resumida história da sedimentação da Formação Piranhas, como ela aparece no lugar do furo LFst-1-Pa.

Depois da deposição dos siltitos e argilitos da Formação Sousa, em ambiente lacustre até pantanoso, durante um período de tranqüilidade tectônica (Braun, 1970; Mabesoone, 1972), houve uma reativação nas linhas estruturais, principalmente na falha de São Gonçalo que limita a área sedimentar ao sul.

A primeira camada que se depositou sob esse novo regime era um siltito argiloso com pequena quantidade de areia fina em zonas, representando o início de pequenas correntes (am. 21).

Bruscamente, essa camada passa a um arenito quartzoso médio com matriz argilosa, o que significa que o solo que cobriu as bordas da "bacia" sedimentar havia desaparecido, começando a aflorar parte da rocha fresca (am. 20).

A intensidade tectônica aumentou consideravelmente, constituindo-se um relevo forte ao sul da bacia, com erosão rápida e deposição por meio de rios em cones aluviais de arenitos arcosianos (am. 19). Essa primeira reativação não durou muito tempo, voltando um período de bastante tranqüilidade, do qual resta ainda um siltito argiloso com bastante óxidos de ferro, presumivelmente derivados de solos avermelhados presentes em lugares mais distantes (am. 18).

Novamente a atividade tectônica aumentou, com a resultante deposição de um arenito protoquartzoso médio, como sedimento correlativo do relevo em formação (am. 17). A pulsação tectônica passou, em seguida, por uma fase menos intensa, evidenciada pelo arenito protoquartzoso fino, que segue no perfil (am. 16). Porém a intensidade de movimento aumentou de novo, para depois, mais uma vez, diminuir, como testemunham primeiramente a grauvaca feldspática grosseira (am.15) e depois a grauvaca lítica média (am. 14). O relevo ao sul da bacia de recepção devia ter ficado bem forte. 
Dentro de todas essas oscilações, com alternantes períodos de forte movimento tectônico e relativa calma, segue-se nova fase tranqüila, resultando em deposição de microclásticos, sob a forma de um argilito síltico (am. 13) e um siltito argíloso (am. 12). Como é de se esperar, após essa nova fase tranqüila, um outro movimento produz um arenito protoquartzoso médio, período que durou certo tempo, dada a espessura desse arenito (mais de $10 \mathrm{~m}$; ams. 11 e 10). Segue-se, agora, um argilito síltico (am. 9) de espessura reduzida, antes de iniciar uma seqüência de arenitos imaturos, causada talvez mais por mudança de corrente, tornando o ambiente mais pantanoso do que por diminuição da intensidade do movimento.

Esse movimento sofreu agora, aparentemente, sua maior intensidade, como testemunha um pacote de, pelo menos, $25 \mathrm{~m}$ de arenitos imaturos. A base desse pacote é representada por um arenito arcosiano médio (ams. 7 e 8), seguido por um arenito protoquartzoso fino (am. 6) e, depois, por grauvacas líticas conglomeráticas (ams. 5 e 4). Essa seqüência fica representativa por um relevo bem forte na área-fonte, com erosão e transporte rápido, e uma deposição em cones aluviais ao pé desse relevo.

Depois dessa fase de tectonismo intenso, segue-se mais uma repetição, com, no início, um período de certa tranqüilidade (argilito síltico, am. 3), passando lentamente para uma fase de maior atividade (arenito protoquartzoso síltico, am. 2), para terminar com o último testemunho de um relevo forte com erosão intensa e deposição rápida (grauvaca feldspática média, am. 1). Essa seqüência parece ser incompleta, o que significa que algumas camadas depositadas posteriormente já foram erodidas.

Tabela V - Ritmos na deposição da Formação Piranhas, à base das microfácies compostas

\begin{tabular}{|c|c|c|c|}
\hline Amostra & $\begin{array}{l}\text { Profundidade, } \\
\text { m }\end{array}$ & $\begin{array}{c}\text { Microfácies composta, } \\
\text { tipo }\end{array}$ & Ritmo \\
\hline 1 & $0-5$ & 3 & \multirow{4}{*}{$5 .^{\circ}$} \\
\hline 2 & $5-10$ & 2 & \\
\hline 3 & $10-15$ & 5 & \\
\hline 4 & $15-20$ & 3 & \\
\hline 5 & $20-25$ & 3 & \multirow{5}{*}{$4 .^{\circ}$} \\
\hline 6 & $25-30$ & 2 & \\
\hline 7 & $30-35$ & 4 & \\
\hline 8 & $35-40$ & 4 & \\
\hline 9 & $40-45$ & 5 & \\
\hline 10 & $45-50$ & 1 & \multirow{4}{*}{$3 .^{\circ}$} \\
\hline 11 & $50-55$ & 1 & \\
\hline 12 & $55-60$ & 5 & \\
\hline 13 & $60-65$ & 5 & \\
\hline 14 & $65-70$ & 3 & \multirow{5}{*}{$2 .^{\circ}$} \\
\hline 15 & $70-75$ & 3 & \\
\hline 16 & $75-80$ & 2 & \\
\hline 17 & $80-85$ & 1 & \\
\hline 18 & $85-90$ & 5 & \\
\hline 19 & $90-95$ & 4 & \multirow{3}{*}{$1 .^{\circ}$} \\
\hline 20 & $95-100$ & 1 & \\
\hline 21 & $100-105$ & 5 & \\
\hline
\end{tabular}


Resumindo, a Formação Piranhas do Grupo Rio do Peixe foi depositada num regime rítmico, de intensidades variáveis. A Tab. V apresenta esses ritmos, concluídos da análise de microfácies de uma seqüência clástica de origem continental.

Assim, pode-se concluir que o conceito de microfácies para sedimentos clásticos afossiliferos pode ser aplicado sem maiores dificuldades.

\section{BIBLIOGRAFIA}

BRAUN, O. P. G. - 1970 - Geologia da bacia do Rio do Peixe. XXIV Cong. Bras. Geol., Brasília (DF); Res. Conf. Comun., Bol. Esp. 1: 208-211

CAROZZI, A. V. - 1950 - Contribution à l'étude des rythmes de sédimentation. Arch. Sciènces, Genève, 3: 1-76

CAROZZI, A. V. - 1958 - Micro-mechanisms of sedimentation in the epicontinental environment. Journ. Sedim. Petrology, 28: 133-150

CAROZZI, A. V. - 1960 - Microscopic sedimentary petrography. New York, John Wiley \& Sons, Inc., $485 \mathrm{pp}$.

CAROZZI, A. V. - 1961 - Reef petrography in the Beaverhill Lake Formation, Upper Devonian, Swan Hills area, Alberta, Canada. Journ. Sedim. Petrology, 31: 497-513

CARUZZI, A.V., TIBANA, P. e TESSARl, E. - 1973 - Estudo das microfácies da Formação Bonfim (Cenomaniano) da bacia de Barreirinhas, Brasil. Petrobrás, Ciência-l'écnica-Petróleo, Seção Exploração Petróleo, 6: $86 \mathrm{pp}$.

HEATH, Ch. P., LUMSDEN, D. N. e CAROZZI, A. V. - 1967 - Petrography of a carbonate transgressive-regressive sequence: the Bird Spring Group (Pennsylvanian), Arrow Canyon Range, Clark County, Nevada. Journ. Sedim. Petrology, 37:377-400

MABESOONE, J. M. - 1968 - Sedimentologia. Recife, Univ. Fed. Pernambuco, Imprensa Univ., $473 \mathrm{pp}$.

MABESOONE, J. M. - 1972 - Sedimentos do Grupo Rio do Peixe (Paraíba). XXVI Cong. Bras. Geol., Belém (PA); Res. Comun., Sessőes Técn., Bol. 1: 236

MABESOONE, J. M. - 1973 - Diagênese nos arenitos: exemplos do Nordeste brasileiro. Soc. Bras. Geol., Anais XXVII Cong., Aracaju (SE): no prelo

MEDEIROS, R. A., SCHALLER, H. e FRIEDMAN, G. M. - 1971 - Fácies sedimentares; Análise e critérios para o reconhecimento de ambientes deposicionais. Petrobrás, Ciéncia-Técnica„Petróleo, Seção Exploração Petróleo, 5: 123 pp.

MILLOT, G. - 1964 - Géologie des argiles. Paris, Masson et Cie., Edit., 499 pp.

PETTIJOHN, F.J., POTTER, P. E. e SIEVER, R. - 1972 - Sand and sandstones. Berlin, Springer-Verlag, $618 \mathrm{pp}$. 